\title{
Efficacy of combined glucocorticoid and hyperbaric oxygen therapy against delayed encephalopathy after carbon monoxide poisoning, and its effect on expression of immune-associated cytokines
}

\author{
Na Li, Xiang-En Meng, Hang Li, Dan-Feng Fan, Shu-Yi Pan* \\ Department of Hyperbaric Oxygen, PLA Navy General Hospital, Haidian District, Beijing 100048, China
}

${ }^{*}$ For correspondence: Email: ut1349@163.com

Sent for review: 17 March 2018

Revised accepted: 27 May 2018

\begin{abstract}
Purpose: To study the efficacy of glucocorticoid combined with hyperbaric oxygen therapy for the treatment of delayed encephalopathy after carbon monoxide poisoning (DEACMP), and its effect on the expression of immune-associated cytokines.

Methods: A total of 102 DEACMP patients in PLA General Hospital, Haidian, China were divided into two groups of 51 patients each, namely, observation group (glucocorticoid + hyperbaric oxygen therapy), and control group (hyperbaric oxygen only). The clinical data for each group was retrospectively analyzed. Clinical efficacy, improvement time, hospitalization time, cognitive function, activities associated with daily living, changes in immunity-associated cytokines, and incidence of adverse reactions were compared for the two groups.

Results: Following treatment, the time taken for improvement, duration of hospitalization, cognitive function, daily living activity and total effectiveness in the observation group were significantly higher than those for the control group $(p<0.05)$. In addition, the levels of transforming growth factor beta 1 (TGF- $\beta 1$ ), interleukin 4 (IL-4) and interferon-gamma (IFN-y) in the observation group were significantly greater than for the corresponding control group levels $(p<0.05)$. There was no significant difference in incidence of adverse reactions between the two groups $(p>0.05)$.

Conclusion: These results suggest that a combination therapy of glucocorticoid and hyperbaric oxygen therapy for the treatment of DEACMP is more eutherapeutic in the improvement of cognitive function and activities of daily living in DEACMP patients than hyperbaric oxygen therapy. The mechanism of this combination therapy may be related to the improvement in immunity-related cytokine levels.
\end{abstract}

Keywords: Glucocorticoid, Hyperbaric oxygen, Delayed encephalopathy after carbon monoxide poisoning, Efficacy, Immunity

This is an Open Access article that uses a funding model which does not charge readers or their institutions for access and distributed under the terms of the Creative Commons Attribution License (http://creativecommons.org/licenses/by/4.0) and the Budapest Open Access Initiative (http://www.budapestopenaccessinitiative.org/read), which permit unrestricted use, distribution, and reproduction in any medium, provided the original work is properly credited.

Tropical Journal of Pharmaceutical Research is indexed by Science Citation Index (SciSearch), Scopus, International Pharmaceutical Abstract, Chemical Abstracts, Embase, Index Copernicus, EBSCO, African Index Medicus, JournalSeek, Journal Citation Reports/Science Edition, Directory of Open Access Journals (DOAJ), African Journal Online, Bioline International, Open-J-Gate and Pharmacy Abstracts

\section{INTRODUCTION}

In acute carbon monoxide poisoning (ACMP), the binding of carbon monoxide to hemoglobin produces toxins in histiocytes of the whole body, resulting in the loss of oxygen carrying capacity and asphyxia of body tissues $[1,2]$.

Although the toxicity symptoms in some patients may be gradually reduced after rescue, this 
poisoning can seriously damage the cerebral cortex, and delayed encephalopathy after carbon monoxide poisoning (DEACMP) may be induced again after several weeks of latent phase $[3,4]$. At present, hyperbaric oxygen therapy is provided in clinical practice because of unknown pathogenesis of DEACMP, long treatment circle, poor curative effects and high disabling rate. However, the clinical effectiveness of hyperbaric oxygen therapy is variable due to different oxygen uptake criteria [5].

It has been reported that glucocorticoid combined with hyperbaric oxygen therapy is clinically eutherapeutic, and that the good brainprotective effect of glucocorticoid can effectively reduce the incidence of DEACMP $[6,7]$. However, there is still lack of specific bases and clinical evidence to back up these findings.

In the present study, the clinical data of 102 DEACMP patients in PLA General Hospital, Haidian were retrospectively analyzed, and the efficacy of combined glucocorticoid and hyperbaric oxygen therapy, as well as its effects on immune-associated cytokines were investigated. This was with a view to providing a theoretical bases for clinical treatment of DEACMP.

\section{METHODS}

\section{General information}

From January 2016 to June 2017, the clinical data for 102 DEACMP patients on admission at PLA General Hospital, Haidian were retrospectively analyzed, and the patients were divided into two groups of 51 members each, according to therapy: observation group and control group. This study was approved by the Ethics Committee of PLA General Hospital, Haidian (approval no. PHG20150526) and followed the guidelines of Declaration of Helsinki [8]. All patients and/or their families signed the informed consent document.

The inclusion criteria were as follows: patients who conformed to DEACMP diagnostic criteria [9]; patients with a previous history of hyperbaric oxygen therapy, and patients with complete clinical data. The exclusion criteria were as follows: patients with diseases that affect final evaluation of treatment efficacy, such as complicated cranio-cerebral trauma, epilepsy, cerebrovascular diseases or other mental disorders; patients unsuited for glucocorticoid use due to active peptic ulcer, diabetes or active tuberculosis; patients who received glucocorticoids within one month before carbon monoxide poisoning; and women in gestation or lactation period. There was no significant difference in baseline data such as sex and age between the two groups $(p>0.05)$, and all data were comparable.

\section{Treatments}

After admission, all the patients received conventional intravenous infusion of cerebroprotein hydrolysate injection, and medications such as Sanqipanaxnotoginseng and ganglioside. The patients in the control group received hyperbaric oxygen therapy with a hyperbaric chamber pressure of $0.2 \sim 0.25 \mathrm{MPa}$ (the hyperbaric oxygen chamber used here was produced by Yantai Haiyue Oxygen Industry Technology Co., Ltd). In the hyperbaric chamber, patients were successfully subjected to a 20-min decompression, 80-min pressure stabilization, 70-min pure oxygen treatment, and 10-minrest for breathing chamber air, after which they went out of the chamber. The therapy was given once a day for 10 successive days which constituted a treatment course, and then stopped for three days before the start of a new treatment course. All patients underwent four treatment courses in total. The patients in the observation group received glucocorticoid treatment in combination with the hyperbaric oxygen therapy of the control group. The above steps for the hyperbaric oxygen therapy were repeated in the observation group. The therapy of hydrocortisone was as follows: $300 \mathrm{mg}$ hydrocortisone (National Medical No. H31021400, product of Shanghai General Pharmaceutical CO. Ltd.) was added to $250 \mathrm{~mL}$ of $5 \%$ glucose, and dripped $3-4 \mathrm{~h}$, gradually decreased and stopped after 2 weeks.

\section{Main outcome measures}

Comparison of improvement time, hospitalization time and clinical efficacy after four treatment courses between the two groups was made.

\section{Therapeutic criteria [10]}

\section{Recovery}

This was based on the following features: clinically asymptomatic, completely self-caring, and completely normal on electroencephalograph (EEG).

\section{Effectiveness}

The features were: clinically partially symptomatic, partially self-caring, and partially normal on EEG. 


\section{Ineffectiveness}

This was marked by absence of any improvement and is expressed as in Eq 1.

$T=(R+E) / N$

where $T$ is total effectiveness rate; $R$ is number of recovered cases; $E$ is number of effective cases; and $N$ is total number of cases in this study.

Cognitive function and activity of daily living before treatment and after 4 treatment courses in the two groups were compared. Cognitive function was assessed by the Mini-Mental State Examination scale (MMSE) [11], which covers six parameters i.e. orientation, memory, attention, computing capacity, linguistic capacity and recall capacity. The total score of the scale was 30 points, and the higher the score, the better the cognitive function.

Activity of daily living was assessed by the Activity of Daily Living scale (ADL) [12], which covers ten parameters i.e. defecation, urination, self-feeding, toilet hygiene, activities, dressing, grooming, transferring, bathing and showering, and stair activity. The total score of the scale was 100 points, and the higher the score, the better the activity of daily living.

\section{Assessment of immune-associated cytokines}

Fasting venous blood $(5 \mathrm{~mL})$ was collected in the morning from each patient and centrifuged at $4000 \mathrm{rpm}$ for $10 \mathrm{~min}$ to obtain serum which was kept in a refrigerator $\left(-20^{\circ} \mathrm{C}\right)$ prior to use. The levels of transforming growth factor- $\beta 1$ (TGF- $\beta 1$ ), interferon-gamma (IFN-y), interleukin 4 (IL-4) and interleukin 10 (IL-10) were determined in the serum samples using enzyme-linked immunosorbent assay (ELISA) kits (Beijing Zhongshan Jinqiao Biology Co. Ltd.) according instructions in the kit manual. Incidents of adverse reactions were recorded in the two groups.

\section{Statistical analysis}

Statistical analysis was performed using SPSS 19.0 statistical software. Numerical data were expressed as percentage (\%), and the $x^{2}$ tests and Yates' correction were used for group comparison $(n \geq 40,1 \leq T<5)$. Measurement data were expressed as mean \pm standard deviation (mean $\pm S D$ ), and Student's $t$-test was used for group comparison. $P<0.05$ was considered statistically significant.

\section{RESULTS}

\section{Demographic and general information}

Table 1 shows that there was no significant difference in general data such as sex and age between the two groups $(p>0.05)$.

\section{Improvement time, hospitalization time and clinical efficacy}

After treatment, the time taken before improvement, and hospitalization time in the observation group were shorter than those in the control group, and the total effectiveness was significantly higher in the observation group than in the control group ( $p<0.05$; Table 2).

Table 1: Demographic and general information $\{n(\%)$, mean \pm SD $\}$

\begin{tabular}{|c|c|c|c|c|c|c|}
\hline \multirow{2}{*}{ Group } & \multirow{2}{*}{$\begin{array}{c}\text { Sex } \\
\text { (Male/female) }\end{array}$} & \multirow{2}{*}{$\begin{array}{c}\text { Age } \\
\text { (Years) }\end{array}$} & \multirow{2}{*}{$\begin{array}{l}\text { Latent phase } \\
\text { (d) }\end{array}$} & \multicolumn{3}{|c|}{ Severity of disease } \\
\hline & & & & Mild & Moderate & Severe \\
\hline $\begin{array}{l}\text { Observation } \\
(n=51)\end{array}$ & $35 / 16$ & $41.35 \pm 5.26$ & $12.67 \pm 2.11$ & $20(39.22)$ & $15(29.41)$ & $16(31.37)$ \\
\hline Control $(n=51)$ & $32 / 19$ & $42.03 \pm 7.59$ & $13.02 \pm 4.43$ & $22(43.14)$ & 16(31.37) & $13(25.49)$ \\
\hline$t / x^{2}$ & 0.391 & 0.526 & 0.509 & & 0.578 & \\
\hline$p$ & 0.532 & 0.615 & 0.626 & & 0.563 & \\
\hline
\end{tabular}

Table 2: Improvement time, hospitalization time and clinical effectiveness (mean $\pm S D$ )

\begin{tabular}{|c|c|c|c|c|c|c|}
\hline \multirow[b]{2}{*}{ Group } & \multirow{2}{*}{$\begin{array}{c}\text { Improvement } \\
\text { time (days) }\end{array}$} & \multirow[b]{2}{*}{$\begin{array}{l}\text { Hospitalization } \\
\text { time (days) }\end{array}$} & \multicolumn{4}{|c|}{ Clinical efficacy } \\
\hline & & & Recovered & Effective & Ineffective & $\begin{array}{c}\text { Total } \\
\text { effectiveness }\end{array}$ \\
\hline $\begin{array}{l}\text { Observation } \\
(n=51)\end{array}$ & $7.25 \pm 3.25$ & $37.62 \pm 9.58$ & $27(52.94)$ & $18(35.29)$ & $6(11.76)$ & $45(88.24)$ \\
\hline $\begin{array}{l}\text { Control }(n=51) \\
t / X^{2} \\
P\end{array}$ & $\begin{array}{c}10.29 \pm 2.97 \\
4.931 \\
0.000\end{array}$ & $\begin{array}{c}42.17 \pm 11.25 \\
2.199 \\
0.030\end{array}$ & $20(39.22)$ & $17(33.33)$ & $14(27.45)$ & $\begin{array}{c}37(72.55) \\
3.980 \\
0.046 \\
\end{array}$ \\
\hline
\end{tabular}


Cognitive function and activities of daily living

After treatment, the scores of MMSE and ADL were higher than those before treatment in the two groups, and the scores in the observation group were significantly higher than those in the control group ( $p<0.05$; Table 3$)$.

\section{Immunity-related cytokines}

In the two groups, the levels of TGF- $\beta 1$ and IL-4 after treatment were higher than those before treatment, and the level of IFN- $\gamma$ was significantly lower than before treatment $(p<0.05)$. However, after treatment, the levels of TGF- $\beta 1$ and IL-4 in the observation group were significantly higher than those in the control group and the level of IFN- $y$ was significantly lower than in control group $(p<0.05)$. There was no significant difference in level of IL-10 between the two groups before and after treatment $(p<0.05)$. These results are shown in Table 4.

\section{Adverse reactions}

No adverse reactions were found in the control group after treatment. There were five cases of adverse reactions in the observation group, including three stress ulcers, one hyperglycemia and one hypertension. However, all adverse reactions returned to normal within one week after drug discontinuance, and the courses of treatment were not affected. After treatment, there was no significant difference in incidence of adverse reactions between the two groups $\left(x^{2}\right.$ test with Yates' correction: 3.365, $p=0.067$ ).

\section{DISCUSSION}

DEACMP is a specific manifestation of brain injury caused by carbon monoxide poisoning, the specific pathogenesis of which is still unclear. At present, hyperbaric oxygen therapy is clinically used in most cases to correct the oxygen deficiency of brain tissues and alleviate the paralysis of capillary vessels [13]. However, longterm clinical observations and studies have found that the efficacy of hyperbaric oxygen therapy is not usually obvious [14]. In recent years, some studies have shown that the incidence of DEACMP can be significantly reduced by combined use of glucocorticoid and hyperbaric oxygen treatment, which resulted in significantly improved recovery rate [15].

The present study showed that the total effectiveness in the observation group was higher than that in the control group, suggesting that the efficacy of glucocorticoid combined with hyperbaric oxygen therapy for DEACMP was better than that of simple hyperbaric oxygen therapy. This is consistent with earlier observations [15]. In addition, the use of glucocorticoid for the treatment of DEACMP showed better brain-protective effects, preferable clinical efficacy, and shorter times of improvement and hospitalization.

Table 3: Cognitive function and activities of daily living (mean \pm SD)

\begin{tabular}{lcccc}
\hline & \multicolumn{2}{c}{ MMSE score (points) } & \multicolumn{2}{c}{ ADL score (points) } \\
\cline { 2 - 5 } Group & Before treatment & After treatment & Before treatment & After treatment \\
& & $24.15 \pm 3.05^{\#}$ & $46.35 \pm 3.15$ & $90.16 \pm 5.28^{\#}$ \\
Observation $(n=51)$ & $13.15 \pm 2.96$ & $20.17 \pm 2.97^{\#}$ & $47.19 \pm 3.46$ & $86.34 \pm 5.01^{\#}$ \\
Control $(n=51)$ & $13.60 \pm 3.05$ & 6.676 & 1.236 & 3.748 \\
$T$ & 0.756 & 0.000 & 0.219 & 0.000 \\
$P$ & 0.451 & &
\end{tabular}

Note: ${ }^{\#} p<0.05$, compared with values before treatment

Table 4: Immune-related cytokines between (mean \pm SD)

\begin{tabular}{|c|c|c|c|c|c|c|c|c|}
\hline \multirow[b]{2}{*}{ Group } & \multicolumn{2}{|c|}{ TGF- $\beta 1 （ \mathrm{ng} / \mathrm{mL})$} & \multicolumn{2}{|c|}{ IFN-y（pg/mL） } & \multicolumn{2}{|c|}{ IL-4（pg/mL） } & \multicolumn{2}{|c|}{ IL-10 (pg/mL) } \\
\hline & $\begin{array}{c}\text { Before } \\
\text { treatmen } \\
t\end{array}$ & $\begin{array}{c}\text { After } \\
\text { treatment }\end{array}$ & $\begin{array}{c}\text { Before } \\
\text { treatmen } \\
t\end{array}$ & $\begin{array}{c}\text { After } \\
\text { treatment }\end{array}$ & $\begin{array}{c}\text { Before } \\
\text { treatmen } \\
t\end{array}$ & $\begin{array}{c}\text { After } \\
\text { treatment }\end{array}$ & $\begin{array}{c}\text { Before } \\
\text { treatmen } \\
t\end{array}$ & $\begin{array}{c}\text { After } \\
\text { treatmen } \\
t\end{array}$ \\
\hline $\begin{array}{l}\text { Observati } \\
\text { on }(n=51)\end{array}$ & $\begin{array}{c}29.58 \pm 5 \\
30\end{array}$ & $\begin{array}{c}39.56 \pm 4.2 \\
0^{\#}\end{array}$ & $\begin{array}{c}28.95 \pm 6 . \\
31\end{array}$ & $\begin{array}{c}14.15 \pm 3.9 \\
7^{\#}\end{array}$ & $\begin{array}{c}25.72 \pm 4 \\
36\end{array}$ & $\begin{array}{c}39.52 \pm 10.2 \\
0^{\#}\end{array}$ & $\begin{array}{l}23.15 \pm 5 . \\
26\end{array}$ & $\begin{array}{c}24.64 \pm 6 . \\
02\end{array}$ \\
\hline $\begin{array}{l}\text { Control } \\
(n=51)\end{array}$ & $\begin{array}{c}28.94 \pm 4 \\
92\end{array}$ & $\begin{array}{c}33.17 \pm 3.9 \\
8^{\#}\end{array}$ & $\begin{array}{c}28.49 \pm 5 \\
72\end{array}$ & $\begin{array}{c}20.52 \pm 3.1 \\
8^{\#}\end{array}$ & $\begin{array}{c}26.10 \pm 5 . \\
28\end{array}$ & $32.17 \pm 6.95$ & $\begin{array}{c}23.36 \pm 5 . \\
58\end{array}$ & $\begin{array}{c}24.13 \pm 5 . \\
89\end{array}$ \\
\hline$t$ & 0.632 & 7.887 & 0.386 & 8.943 & 0.396 & 4.253 & 0.196 & 0.432 \\
\hline$P$ & 0.529 & 0.000 & 0.701 & 0.000 & 0.693 & 0.000 & 0.841 & 0.666 \\
\hline
\end{tabular}


The results considered that glucocorticoid drugs with immunosuppressive actions can regulate neurophysiological functions of the body, resulting in the reductions in lipid peroxide contents and toxicity of amino acid in spinal cord of head, which promotes the rehabilitation of patients and achievement of expected efficacy [16]. Therefore, combined treatment with hyperbaric oxygen therapy and glucocorticoid is more effective. Studies have shown that methylprednisolone combined with memantine hydrochloride produces marked clinical effects in the treatment of Parkinson disease patients with neurological dysfunction caused by carbon monoxide poisoning [17]. The present study also showed that after treatment, the cognitive function and daily living activities in the observation group were better than those in the control group, indicating that glucocorticoid can effectively promote the recovery of nerve function. It is likely that the actions of glucocorticoids in stabilizing biomembranes and increasing vascular density resulted in enhanced immunosuppressive functions.

The immunosuppressive functions of glucocorticoids promote dilatation of constricted and spastic blood vessels, improvement of cerebral blood circulation, increase in neural excitability, and reduction of carbon monoxide-induced axoneuron damage $[18,19]$. Other clinical studies show that glucocorticoids, apart from having therapeutic effects on nervous system injuries caused by carbon monoxide poisoning, also exert prophylactic effects via reducing the incidence of DEACMP [20]. However, these are only preliminary clinical studies. Thus, more indepth studies on large sample sizes are needed.

Some scholars have found that DEACMP-linked damages are not only associated with anaerobic mechanism, but also closely related to abnormal immunologic function [21]. The mechanism of this abnormal immunologic function is associated with the production of malondialdehyde (a lipid peroxide) and activation of myelin basic protein and intrathecal peroxidase, which result in brain damage due to infiltration of macrophages, neutrophilic granulocytes and lymphocytes [22]. Indicators such as IFN- gamma, TGF- $\beta 1$, IL-4 and IL-10 influence immuno-regulation. Indeed, IFN- gamma participates in immune and inflammatory responses, and TGF- $\beta 1, \mathrm{IL}-4$ and IL-10 belong to intrinsic inhibitory cytokines $[23,24]$.

This study showed that the levels of TGF- $\beta 1$ and IL-4 in the observation group were higher than those in the control group. Previous studies have reported that the incidence of DEACMP is closely related to the level of immune-associated cytokines [25]. IFN- $\gamma$ enhances cellular immunologic responses, inhibits production of antibodies and promotes inflammatory responses [26]. It has been shown that TGF- $\beta 1$ and IL-4 play feedback-negative regulatory roles in immune function through maintenance of balance between intercellular and intracellular cytokines in the immune system $[27,28]$. The results obtained in this study indicate that glucocorticoid combined with hyperbaric oxygen therapy can significantly decrease IFN-y level, increase TGF- $\beta 1$ and IL-4 levels, and reduce inflammatory reactions, thereby resulting in significant amelioration of DEACMP-induced lesions. The Guidelines for Clinical Treatment of Carbon Monoxide Poisoning suggests that glucocorticoid cannot be used as a conventional clinical therapeutic method due to its selflimitations, and may be used in clinical practice as appropriate only when there are serious complications such as DEACMP without hormonal contraindications in ACMP patients.

Although glucocorticoid combined with hyperbaric oxygen therapy caused a few adverse reactions in this study, there were no statisticallysignificant differences when compared with simple hyperbaric oxygen therapy. Moreover, the adverse reactions had minimal effects on therapeutic efficacy because they all disappeared after drug discontinuance. On the other hand, glucocorticoid combined with hyperbaric oxygen therapy was relatively safe for the treatment of DEACMP, because long-term use of hormone was not needed during treatment, and all changes in indices of patients were closely observed for effective prevention of adverse reactions.

\section{Study limitations}

The small sample size of this study made statistical bias more likely. Moreover, studies on long-term efficacy of the combination therapy were not performed. Thus, deeper, multi-center studies with larger sample sizes are necessary.

\section{CONCLUSION}

Combined therapy of glucocorticoid and hyperbaric oxygen therapy is eutherapeutic for the treatment of DEACMP, and can significantly shorten the times of improvement and hospitalization while enhancing recovery of cognitive function and daily life activities. The mechanism involved in these effects is associated with improvement in the level of immune-associated cytokines. 


\section{DECLARATIONS}

\section{Conflict of Interest}

No conflict of interest associated with this work.

\section{Contribution of Authors}

We declare that this work was done by the author(s) named in this article and all liabilities pertaining to claims relating to the content of this article will be borne by the authors, all authors read and approved the manuscript for publication. Shu-Yi Pan conceived and designed the study, Na Li, Xiang-En Meng, Hang Li, DanFeng Fan collected and analyzed the data, $\mathrm{Na} \mathrm{Li}$ wrote the manuscript.

\section{REFERENCES}

1. Cação G, Freitas J, Neves S, Camacho O, Damásio J. Chorea in acute carbon monoxide intoxication. NeurolSci2018; 39(1):197-198.

2. Varrassi M, Di Sibio A, Gianneramo C, Perri M, Saltelli G, Splendiani A, Masciocchi C. Advanced neuroimaging of carbon monoxide poisoning. Neuroradiol J 2017; 30(5): 461-469.

3. Yoshiike $T$, Nishida M, Yagishita K, Nariai T, Ishii $K$, Nishikawa T. Altered sleep spindles in delayed encephalopathy after acute carbon monoxide poisoning. J Clin Sleep Med 2016; 12(6): 913-915.

4. Oh S, Choi SC. Acute carbon monoxide poisoning and delayed neurological sequelae: a potential neuroprotection bundle therapy. Neural Regen Res 2015; 10(1): 36-38.

5. Watanuki T, Matsubara $T$, Higuchi N. Clinical examination of 3 patients with delayed neuropsychiatric encephalopathy induced by carbon monoxide poisoning, who recovered from severe neurocognitive impairment by repetitive hyperbaric oxygen therapy. Seishin Shinkeigaku Zasshi 2014; 116(8): 659-669.

6. Tang Q, Li Y, Wang YY, Ye ML, Zhang F, Liu Q, Wang H, Wang $Y$. Glucocorticoids and high pressure oxygen in prevention and treatment of delayed encephalopathy after acute carbon monoxide poisoning: a meta-analysis for efficacy and safety. Acta Acad Med Mil Tert 2016;38(2):207-214.

7. Zhong XQ, Du JX, Li CHX. Clinical study on efficacy of intermittent long-course hyperbaric oxygen therapy combined with Methylprednisolone for treatment of DEACMP. Medical Journal of National Defending Forces in Northwest China 2016;37(5):334-335.

8. Williams JR. The Declaration of Helsinki and public health. Bull World Health Organ 2008; 86(8): 650-652.

9. Tian FX, Qu YC, Gao QL. Related risk factors and early diagnosis of delayed encephalopathy from acute carbon monoxide poisoning. Hainan Med J 2016; 27(5): 782784.
10. Lu X, Akbar H, Zhang JJ. The value on the evaluation of classification of EEG reactivity for diagnosis of early stage and prognostic of delayed encephalopathy caused by acute carbon monoxide poisoning. Chin Med Equi 2017; 14(8): 84-87.

11. Ahn SH, Choi JH, Im CS, Kim TS, Kim JL. Comparison of the Severe Cognitive Impairment Rating Scale with the Mini-Mental State Examination and Delirium Rating Scale-Revised-98 for Delirium: A Cross-sectional Study. Psychosomatics 2017; 58(6): 643-651.

12. de Paula JJ, Albuquerque MR, Bicalho MAC, RomanoSilva MA. Confirmatory factor analysis of the general activities of daily living scale: further evidences of internal validity. Rev Bras Psiquiatr 2017; 39(4): 379380.

13. Bidstrup D, Jansen EC, Hyldegaard O. Quantitative Romberg's test in acute carbon monoxide poisoning treated by hyperbaric oxygen. Undersea Hyperb Med 2017; 44(6): 559-567.

14. Huang CC, Ho CH, Chen YC, Lin HJ, Hsu CC, Wang JJ, Su SB, Guo HR. Hyperbaric oxygen therapy is associated with lower short- and long-term mortality in patients with carbon monoxide poisoning. Chest 2017; 152(5): 943-953.

15. Xiang W, Xue H, Wang B, Li Y, Zhang J, Jiang C, Liang F, Pang J, Yu L. Combined application of dexamethasone and hyperbaric oxygen therapy yields better efficacy for patients with delayed encephalopathy after acute carbon monoxide poisoning. Drug Des Dev Ther 2017; 11: 513-519.

16. Leong SH, Shander S, Ratnasingam J. Predicting recovery of the hypothalamic-pituitary-adrenal axis after prolonged glucocorticoid use. Endocr Pract 2018; 24(1): 14-20.

17. Iwamoto K, Ikeda K, Mizumura S, Tachiki K, Yanagihashi $M$, Iwasaki $Y$. Combined treatment of methylprednisolone pulse and memantine hydrochloride prompts recovery from neurological dysfunction and cerebral hypoperfusion in carbon monoxide poisoning: a case report. J Stroke Cerebrovasc Dis2014; 23(3):592595.

18. Lv XP, Deng Y. Research progress in the delayed encephalopathy after carbon monoxide poisoning. Medical Recapitulate 2017;23(1):100-103.

19. Clarisse D, Thommis J, Van WK, Houtman R, Ratman D, Tavernier J, Offner F, Beck I, De BK. Coregulator profiling of the glucocorticoid receptor in lymphoid malignancies. Oncotarget2017;8(65):109675-109691.

20. Li H, Zhang M, Zhang D, Ma L, Bu T, Tian J. Effect of early hormone intervention on delayed encephalopathy after carbon monoxide poisoning. J Clin Emerg 2015; 16(4): 256-259.

21. Liu $X$, Wang $Y Y$, Jin $Y$. Advances in the study on glucocorticoid for the treatment of delayed encephalopathy after acute carbon monoxide poisoning. Chinese J Industr Med 2015; 28(1): 32-35.

22. Yin TL, Yu FCH. Clinical manifestations and prognosisrelated factors of delayed encephalopathy due to acute

Trop J Pharm Res, June 2018; 17(6): 1182 
carbon monoxide poisoning. Chin J Geriatr Heart Brain Ves Dis 2015; 17(8): 844-846.

23. Molofsky $A B$, Van Gool F, Liang HE, Van Dyken SJ, Nussbaum JC, Lee J, Bluestone JA, Locksley RM. Interleukin-33and interferon-y counter-regulate group 2 innate lymphoid cell activation during immune perturbation. Immunity2015; 43(1): 161-174.

24. Abhimanyu, Bose M, Varma-Basil M, Jain A, Sethi $T$, Tiwari PK, Agrawal A, Banavaliker JN, Bhowmick KT. Establishment of elevated serum levels of IL-10, IL-8 and TNF- $\beta$ as potential peripheral blood biomarkers in tubercular lymphadenitis: a prospective observational cohort study. PLoS One 2016; 11(1): e0145576.

25. Yu XL, Liu $L Q, W u Y$, Ouyang $X C$, Wang $S H$, Xiong WJ, Zhang $C P$, Jing SW. Carbon monoxide poisoning and delayed encephalopathy associated with expression of immune related cytokines in serum. Chin $\mathrm{J}$ Immun 2014; 30(1): 121-122.

26. Yang MF, Jiang LQ. Effect of acupuncture intervention on the intestinal mucosal inflammatory response and immune response balance in animals with ulcerative colitis. J Hainan Med Univ2017; 23(13): 1744-1747.

27. Kohyama M, Sugahara D, Hosokawa $H$, Kubo M, Hozumi $N$. IL-4-mediated development of TGF- $\beta 1$-producing cells from naive CD4+ Tcells through a STAT6independent mechanism. Eur J Immunol 2015; 31(12): 3659-3666.

28. Li HL, Gao MH, Zheng YH, Yang SJ, Liu YQ, Lu WP. Study on levels of IFN-y,IL-6,IL-17 and TGF- $\beta 1$ in patients with Graves' disease. Chin J Immun2015; 31(2): 253-256 